\title{
Mental health distress and academic performance of medical students: a review
}

\begin{abstract}
Medical education is stressful in pursuing the courses and career of medical professionals. On the other hand, medical education is perceived as being stressful, and a high level of stress may have the unhelpful effect on cognitive functioning and learning of students. The research method was based on the review of recent research literature from PubMed, WHO, PsycINFO, and Global Health. Psychiatrists provide the treatment to the students, which are critical to consider transference and counter transference issues, over professionalism, and instances of strong respects and recognition. And it's better to understand the goal of medical education is expected to train knowledgeable, competent, and professional physicians equipped to care for the sick people, advance the science of medicine, and promote public health. Patterns of proceeding to the school, and personality traits, support systems, and many other factors, affect who will experience stress and their ability to deal with it. Therefore, this systematic review journal indicated many perspectives and arguments about the mental health distress of medical students.
\end{abstract}

Keywords: mental health, distress, wellness, academic performance, medical students
Volume 9 Issue 6 - 2018

\author{
Liranso G Selamu,' Mohan S Singhe ${ }^{2}$ \\ 'PhD Scholar in Social Work, Mangalore University, India \\ ${ }^{2}$ Research guide, Mangalore University, India
}

Correspondence: Liranso G Selamu, PhD Scholar in Social Work, Mangalore, India, Email iramso.2006@gmail.com

Received: May 26, 2017 | Published: November 26, 2018

\section{Introduction}

A medical school in many countries is very highly expressively difficult, and the school life is quite stressful than other higher education. ${ }^{1}$ Furthermore, university life is much different especially medical school than high school. As students need to live alone and less supported condition, and copying with the high pressure of study demands of the program is often tough for young folks. ${ }^{2}$ Medical students are predominantly suffers from stress during their course as because of academic pressure, classicist criteria and tough nature of medical practice which requires involvement with human suffering, death, sexuality and fear. ${ }^{3}$ Besides, at many occasion stress lead to poor physical health, mental distress, reduce students' self-esteem and have a negative effect on cognitive functioning and learning of students in the medical school..$^{4-6}$ Multiple researches reported that stress damages psychological health. Therefore causes anxiety and depression in medical students not only in advance countries but also developing countries. ${ }^{7}$ Psychological distress is a subjective experience. In other words, psychological discomfort may interfere with different subjective experiences and activities. Psychological distress can result in negative views of the environment, others, and the self. Sadness, anxiety, distraction, and symptoms of mental illness are manifestations of psychological distress. That is, the severity of psychological distress is dependent upon the situation and how we perceive it. We can think of psychological distress as a continuum with mental health and mental illness at opposing ends. As we continue to experience different things, we travel back and forth on the continuum at different times throughout our lives. Additionally, psychological distress is a term used to describe the general psychopathology of an individual with a combination of depressive symptoms, anxiety and perceived stress. Included in this compilation are topics corresponding to mitigating adverse school experiences and psychological distress with parental support; psychological distress in an ecological context; screening for psychological distress in clinical practice; psychological distress scale and psychological distress. An increasing number of students are arriving on college campuses with mental health issues. ${ }^{8}$ It is not uncommon for students to experience varying degrees of stress, anxiety, and depression during their time in college, as well as they encounter both academic and other stresses during their college experience. Some examples of non-academic stressors include personal relationships, work life, and family. Even a major life transition such as moving away from home to college can aggravate existing mental illnesses or trigger new ones ${ }^{9}$ College student mental health issues have been on the rise, especially in recent decades. According to Hunt \& Eisenberg, ${ }^{8}$ this rise may be a reflection of increased willingness among students to report these types of issues, rather than an increase of mental health issues. An increased awareness about these issues may have reduced the stigma associated with seeking help. Improved identification of mental health issues coupled with better mental health treatment options mean that students whose severe mental health challenges may have precluded them from going to college in the past are now able to attend college. More than $91 \%$ of college counseling center directors reported a rising trend of students with severe psychological problems on their campuses. ${ }^{10}$

Likewise, medical school is a time of significant psychological distress for physicians in training. Currently available information is insufficient to draw firm conclusions on the causes and consequences of student distress. Large, prospective, multicenter studies are needed to identify personal and training related features that influence depression, anxiety, and burnout among students and explore relationships between distress and competency. Prevalence of psychological distress amongst medical students is substantial. Future research should move on from simple cross sectional studies to better quality longitudinal work which can identify both predictors for and 
outcomes of poor mental health in medical students. Psychological distress and low peer social support may synergistically increase the probability of poor academic self perception among international medical students. Promoting peer social relationships at medical school may interrupt the vicious cycle of psychological distress and poor academic performance. ${ }^{11}$ Causes of psychological distress are traumatic experiences, such as the death of a loved one, are causes of psychological distress. Psychological distress can be thought of as a maladaptive response to a stressful situation. Psychological distress occurs when external events or stressors place demands upon us that we are unable to cope with. For example, we may struggle to accept that a loved one is no longer with us. As a result, we become sad and have trouble getting out of bed, we are unable to focus at work, and we lose interest in social activities. ${ }^{11}$ Major life transitions moving to a new state or graduating from college, can be a source of psychological stress if you are unable to cope with the demands that these transitions place on you or are having difficulty adjusting to the new situation. Sudden unexpected events, such as a loved one's death of a heart attack or being fired from a job, can also cause psychological distress. Even everyday stressors, such as traffic, have the potential to cause psychological distress. Some other sources of psychological distress include: cancer and other medical illness, divorce, starting a new job, being a victim of bullying, adverse school experiences, adverse work experiences, infertility, and mental illness. ${ }^{12}$

\section{Method}

The research method was based on the review of recent research literature from PubMed, WHO, PsycINFO, and Global Health. The selection of the journals selection was based on the study purpose and the journals only written in English were included. Journals have also been searched with keywords: mental health disorders, academic performance, mental illness and medical education. Relevant journals which directly related to the study purpose were identified and included in the review.

\section{Mental distress and academic performance of medical students}

According to $\mathrm{Hamza}^{13}$ medical education seems as being traumatic, and a high level of strain may have a negative effect on cognitive functioning and learning of students in a medical school. Moreover, the negative effects of long and tiring medical education on the psychological status of students have been shown in several studies. Study results showed that one third of psychologically ill students did not graduate from the college. The changes relating to becoming a medical student appear to have a significant impact on the psychological status of students during the first year in their study. Therefore, with early identification and effective psychological services, possible future illnesses may be prevented. Besides, a high level of stress among the first year and second year students, and supporting them and taking care of this group by the student support system. This will also help them cope well with stress in the later years. It is very important to target stress prevention strategies at students who have any level of psychological stress to prevent the development of more serious conditions relating to stress. Wellness and mental health programs are also needed to help students make smooth transition between different learning environments with changing learning demands and a growing burden on their mental and physical capacity. ${ }^{13}$
Additionally, medical students are exposed to diverse varieties of stress. It is reported during undergraduate medical education stress is related to academic, financial and social. Sometime stress arises from compulsion to succeed and also in difficulties of integrating education system. ${ }^{14}$ Researcher identified stress of medical students are mainly due to curricular overload but not due to personal difficulties. It is because of demanding, intense environment of medical education has created excessive pressure on medical students. ${ }^{15}$ There are number of reports available indicates that medical schools environment is not congenial and friendly to enhance psychological and physical health of students. It is less than $3 \%$ in any population suffers from psychiatric diseases. Similar figure also observed with medical students before taking admission in medical school. ${ }^{16}$ World Health Organization ${ }^{17}$ define mental health "a state of well-being in which an individual realizes his or her own abilities, can cope with the normal stresses of life, can work productively, and is able to make a contribution to his or her community". Some researchers indicated that the consequence of failure of an organism to respond adequately to mental, emotional or physical demands, whether actual or imagined. People even in absence of major psychiatric disorders also suffer from socioculturally and lead to poor physical health and education status. ${ }^{18}$ Good mental health status is imperative to progress and maintain a quality life for each individual. ${ }^{19}$ Most common psychiatric health disorders related to stress are depression and anxiety. ${ }^{20}$ Psychological morbidity in medical students rises sharply to $21 \%$ to $56 \%{ }^{15}$ There are reports that at the end of first year it is doubled which is very alarming. Currently there are a lot of discussions regarding stress of medical students because mental health ensures total health. Research reported three main areas of stress; academic pressures, social issues and financial problems. A number of studies emphasis on the quality of life of medical students which will ensure quality of medical education and hence forth better prescribe on basis of rational use of medicine for this earth. ${ }^{21}$

\section{Symptoms of medical student's mental distress}

As Julie ${ }^{22}$ indicated that medical school is inherently a stressful, challenging academic experience, this may make medical students vulnerable to depression, anxiety, and burnout. The potential psychological distress in medical school students has been studied by various researchers. Subsequent to medical school, life for a practicing physician also often lends itself to a chronically stressful lifestyle. Patterns of coping prior to medical school as well as personality traits, support systems, and many other factors, affect the experience of stress and their ability to deal with it. The psychological distress symptoms (i.e. stress, anxiety and depression) were significantly higher at the end of the first year of medical training than at the beginning. Medical schools should therefore observe their students at the end of the first year particularly near the examination period, to determine whether they need psychological support. Moreover, Julie ${ }^{22}$ indicated that medical school is a stressful and challenging time in the academic career of physicians. Because of the psychological pressure inherent to this process, all medical schools should have easily accessible medical student mental health services. Some schools of medicine provide these services through departments of psychiatry or other associated training programs. Since this stressful lifestyle often continues through residency training and life as a physician, this is a critical period in which to develop and utilize functional and effective coping strategies. When psychiatrists provide the mental health treatment to medical students, it is important to consider transference and counter transference issues, over intellectualism, and instances of 
strong idealization and identification. The experience of mental illness can be very serious for the career of a medical student because of potential impairment but also because of stigma. For this reason, helpseeking may take place far later into the course of the disease than is beneficial for the student and for the community. If the ability existed for students to engage the formal systems earlier without disclosing their personal health information, it may hasten the transition from pre-contemplative to motivate to seek change.

Common mental disorders are usually characterized as disorders that, although initially requiring no psychiatric treatment, later prove to have great socioeconomic impact. Moreover, there are potential underlying causes for the development of more serious mental disorders. Common mental disorders are related to somatoform disorders and to anxiety and depression. Characteristic symptoms include insomnia, fatigue, irritability, forgetfulness, difficulty in concentrating and somatic complaints, though psychotic, personality-related disorders and chemical dependence are not involved as an excerpted. ${ }^{23}$ It is important to acknowledge that mental health conditions can present in a variety of ways, depending upon the individual and the circumstances The most crucial thing is considering, how a person seems in relation to how they usually are. Changes in people's mood and personality can provide important indicators as to how they are feeling. Unusual mood swings or social withdrawal might, for example, provide some indication that the person is experiencing some degree of emotional distress. Essentially, it is difficult to define what is 'normal', other than to use an individual's usual behavior as a point of comparison. Clearly it is not always possible to make such comparisons when dealing with someone for the first time, or with little prior knowledge of them. The following list might help in alerting to the presence of emotional distress: the list is not a diagnostic tool, but rather a collection of signs that might indicate that a person is experiencing some degree of mental health condition: Erratic or unpredictable behavior; agitation or overt anxiety, social withdrawal/avoidance of social interaction or contact, unexplained or prolonged crying, change or disturbance in eating/sleeping patterns. And, incoherent speech, paranoia, physical illness, hearing voices, thought of suicide/harm, and disturbances in routine activities, and loss of interest and curiosity in acquiring new knowledge.

Depression is a common but serious illness that leaves you feeling despondent and helpless, completely detached from the world. Depression is the number one reason students drop out of school, and is a gateway issue that, if left untreated, could lead to other symptoms or suicide. Depression manifests in varying degree from general symptomology to a clinical disorder. Symptoms occur in four general domains of human functioning: emotional, cognitive, physical, and behavioral, with mood disturbance being the predominant feature. Typical symptoms of depression include a change in appetite or weight, sleep, and psychomotor activity; decreased energy; feelings of worthlessness or guilt; difficulty thinking, concentrating, or making decisions; or recurrent thoughts of death or suicidal ideation. Anhedonia, or a loss of interest in activities that were once considered pleasurable, accompany social withdrawal. Depression is a risk factor for a number of other negative health outcomes including diminished immune function and poor illness recovery. ${ }^{24}$ Some studies indicated on the negative effects of student substance use are not campus centered, and impact both the campus and wider communities.

Substance use is associated with increased absenteeism from class and poor academic performance. The majority of injuries, accidents, vandalism, sexual assaults and rape, fighting, and other crime on and off college campus are linked to alcohol and other drug use. Unplanned and uninhibited sexual behavior may lead to pregnancy, exposure to sexually transmitted diseases, and HIV/AIDS. Driving under the influence, tragic accidents, alcohol poisoning, overdosing, and even death from accidents, high risk behaviors, and suicide carry tremendous, life-threatening implications for all involved. Tobacco use is associated with severe health risks and illness, physical inefficiency, and even death. Fires caused by careless smoking practices place all students at risk. Simply experiencing these feelings does not mean you have an anxiety disorder. Anxiety disorders occur when anxiety interferes with your daily life, halting your ability to function, and causing an immense amount of stress and fearful feelings. Symptoms of anxiety disorders can be mistaken for everyday stress or written off as someone worrying too much. Panic attacks may be mistaken as a physical ailment, such as a heart attack or tension headache, depending on how your body responds to the increased levels of certain chemicals. Symptoms manifest differently in each person, so what is true for someone to be true for a friend. Common symptoms for anxiety disorders may include: Feelings of stress and apprehension, irritability, trouble concentrating, fearfulness, sweating and dizziness, shortness of breath, irregular heartbeat, muscle pain and tension, headaches, and frequent upset stomach. The cause of anxiety disorders is not completely understood, but they could include genetics, naturally occurring brain chemicals, life experiences or stress. ${ }^{24}$

\section{Conclusion}

Every medical student should have a family physician; and medical students should be safe to explore experiences of stress within their professional team. Mental illness is a common, growing in population and in the physicians as well. Every medical student will be appropriately and reasonably accommodated by their program to seek care and support for mental illness. People with mental illness not necessarily experience continuous harm that may be limited to certain domains. Further, when people with mental illness are experiencing impairment due to that illness, they should be treated by counsellors and teachers with sensitivity and respect. There are healthy ways to cope with stress, including mindfulness, discussion and maintaining support systems. Medical educators and peers must work to ensure that their behaviours, beliefs and attitudes do not implicitly or explicitly cause undue stress on learners nor reinforce stigma around mental illness. Future research should move on from simple cross sectional studies to better quality longitudinal work which can identify both predictors for and outcomes of poor mental health in medical students. Psychological distress and low peer social support may synergistically increase the probability of poor academic self perception among international medical students. ${ }^{25-36}$

\section{Acknowledgments}

None.

\section{Conflicts of interest}

The author declares that there are no conflicts of interest.

\section{References}

1. Firth J. Levels and sources of stress in medical students. $\mathrm{Br}$ Med J. 1986;292(6529):1177-1180. 
2. Barikani A. Stress in Medical Students. Medical Education 2008;11(1\&2):41-44

3. Shah H, Malik S, Screeramareddy C. Perceived stress sources and severity of stress among medical undergraduates in a Pakistani medical school. BMC Med Educ. 2010;10:2.

4. Dahlin M, Joneborg N, Runeson B. Stress and depression among medical students: a cross-sectional study. Med Edu. 2005;39(6):594604.

5. Dyrbye L, Thomas M, Massie F, et al. Burnout and suicidal ideation among US medical students. Ann Intern Med. 2008;149(5):334-341.

6. Velayudhan A, Gayatridevi S, Rita R. Efficacy of behavioural intervention in reducing anxiety and depression among medical students. Ind Psychiatry J. 2010;19(1):41-46.

7. Martin M, Peterlini M, Saadeh A, et al. Anxiety and depression in the first year of medical residency training. Med Educ. 2002;36(1):66-72.

8. Hunt J, Eisenberg D. Mental health problems and help-seeking behavior among college students. Journal of Adolescent Health. 2010;46(1):310 .

9. Franklin C. Mental health of college students and their non-collegeattending distress among U.S. and Canadian medical students. 2009.

10. Gallagher R. National Survey of Counseling Center Directors. 2008.

11. Al Saadi T, Sarah Z, Tarek T, et al. Psychological distress among medical students in conflicts: a cross-sectional study from Syria. BMC Med Educ. 2017;17(1):173.

12. Gail I, Neil S, Scott D. Stress and health: Psychological, Behavioural, and Biological Determinants. Annu Rev Clin Psychol. 2002:1:607-628.

13. Abdulaziz A, Hamza M, Ebrahim S, et al. Stress and its effects on medical students: a cross-sectional study at a college of medicine in Saudi Arabia. 2001;29(5):516-522.

14. Singh G, Hankins M, Weinman J. Does medical school cause health anxiety and worry in medical students. Med Educ. 2004;38(5):479-481.

15. Yusoff B, Mohamed S. Stress, stressors and coping strategies among secondary school students in a Malaysian government secondary school: Initial findings. ASEAN J Psychiatry. 2011;11(2):143-157.

16. Yusoff AF, Abdul R, Baba S, et al. Prevalence and associated factors of stress, anxiety and depression among prospective medical students. Asian J Psychiatry. 2013;6(2):128-133.

17. WHO. Prevention and promotion in mental health. World Health Organization. Geneva; 2005.

18. Kozier B. Fundamentals of nursing: concepts process and practice. Prentice Hall;2008:181

19. Kitchener A, Bond S, Reavely J, et al. Mental Health First Aid: Supplementary Booklet for Medical Students. Mental Health First Aid Australia: Melbourne; 2002.
20. Richards R, Allen E. Handbook of Psychotherapy and Religious Diversity. Washington, DC: American Psychological Association. 2010:518.

21. WHO. Mental Health in the WHO European Region. Fact Sheet EURO/03/03. Geneva; 2003.

22. Julie P. Medical Student Mental Health Services: Psychiatrists Treating Medical Students. 2009;6(5):38-45

23. Cait C. Mental Health for Medical Students. CFMS. University of Toronto, Canada; 2010.

24. Johann P. Personal and Psychological Problems of College Students Family Dynamics, Depression, Eating Disorders, Substance Use, Other Psychological Disorders, and Campus Services. State University. 2016.

25. Boston University Student Health Services. Identifying Students in Distress 881 Commonwealth Avenue, Boston. 2011.

26. Chew-G, Rogers A, Yassin N. Medical students' experiences of helpseeking for mental health problems. Med Educ. 2003;37:873-880.

27. The psychological impact of infertility and its treatment. Harvard Health Publication: Harvard University Pub. Inc; 2010.

28. Inam B, Saqib A, Alam E. Prevalence of anxiety and depression among medical students of private university. J Pak Med Assoc. 2003;53(2):44-47.

29. Luciano Y. Mental Illnesses Understanding Prediction and Control. InTech Janeza Trdine, Rijeka, Croatia; 2011.

30. Ranna P. American Psychiatric Association. 1000 Wilson Boulevard, Suite 1825, Arlington, Va; 2015.

31. Saipanish R. Stress among medical students in a Thai medica school. Med Teach. 2003;25(5):502-506.

32. Singh P, Nicola C. The relationship between academic assessment and psychological distress among medical students: a systematic review. Perspect Med Educ. 2010;3(6):405-418.

33. Smith P. Psychologist Impairment: What Is It, How Can It Be Prevented and What Can Be Done to Address It? Clinical Psychology: Science and Practice. 2007;16(1):1-15.

34. Storrie M, Kathryn A, Anthony T. A systematic review: Students with mental health problems - A growing problem. Int J Nurs Pract. 2010;16(1):1-6

35. Wilson E, Thalanany M, Shepstone L, et al. Befriending carers of people with dementia: a cost utility analysis. Int J Geriatr Psychiatry. 2009;24(6):610-623.

36. Yolanda W. Ultimate College and Career Guide: College Psychology and Ethics, philosophy in counselor education and supervision. Mountain View, CA; 2016. 